\title{
A PERMANÊNCIA DAS DESIGUALDADES DE SEXo NA FORMAÇÃo DE TÉCNICOS DE NÍVEL MÉDIO NO BRASIL
}

\section{GENDER INEQUALITY IN THE BRAZILIAN TECHNICAL EDUCATION}

Liliane Bordignon ${ }^{1}$

\section{RESUMO}

O artigo analisa a participação de mulheres em cursos técnicos de nível médio no Brasil a partir de estatísticas educacionais extraídas do Censo Escolar MEC/INEP (2011-2013). Parte-se do pressuposto de que no Brasil as barreiras jurídicas e políticas que impediam as mulheres de frequentarem cursos profissionalizantes ou mesmo de se escolarizar já não são a causa da desigual participação de ambos os sexos em cursos técnicos de nível médio como mecânica, mecatrônica, eletroeletrônica, etc. A profissionalização está aberta juridicamente à "livre escolha" dos indivíduos e muito já se avançou quanto a escolarização das mulheres no ensino técnico, principalmente nas últimas quatro décadas. No entanto, a baixa frequência de mulheres em cursos tradicionais permanece e mostra a latência da desigualdade de sexo na formação profissional. A análise dos dados extraídos do Censo Escolar mostra a permanência das desigualdades de sexo nos cursos técnicos tradicionais (mecânica, eletroeletrônica, etc.) e contribuem para a elaboração de um quadro sobre a presença das mulheres no ensino técnico. As diferentes escolhas profissionais parecem ser orientadas pela posição das distintas carreiras na hierarquia do trabalho, historicamente classificadas entre "femininas" e "masculinas" e estão relacionadas aos "papéis" que cada sexo assume na família e na sociedade.

Palavras-chave: ensino técnico - divisão sexual do trabalho - educação.

\begin{abstract}
The paper analyzes the participation of women in technical courses in Brazil using data from the official education statistics (School Census MEC/INEP - 2011-2013). The assumption was that the Brazilian legal and political barriers that usually difficult women to attend to professionalizing courses or to be educated are not actually the cause of the gender inequality found in technical courses such as mechanics, mechatronics, and electroelectronics. The professionalization is legally open for the "free choice" of individuals, and much has been achieved in relation to women's education in technical courses, mainly in the last four decades. However, there is still a low frequency of women in these technical courses, which shows the latency of gender inequality in professional education. The analysis of the data from the School Census shows that gender inequality remains present nowadays in traditional technical courses (e.g., mechanics, mechatronics, and electroelectronics) and contributed to develop a picture on the presence of women in technical courses. Different professional choices are, in general, leaded by the different positions of professional careers in the world, which are historically classified as "feminine" and "masculine", based on the "roles" of each gender in a family unit or in the society.
\end{abstract}

Keywords: Techinical training - gender division of labor - education.

\footnotetext{
${ }^{1}$ LILIANE BORDIGNON - Mestre em Educação. Doutoranda no Programa de Pós-graduação em Educação FEUnicamp. Contato: lilianebordignon@yahoo.com.br.

Revista Labor Fortaleza/CE, jul/dez 2017 Vol. 01, nº 18, p. 16-30 ISSN 1983-5000
} 


\section{INTRODUÇÃO}

O objetivo deste trabalho é analisar a participação de mulheres em cursos técnicos de nível médio no Brasil a partir de estatísticas educacionais oficiais (Censo Escolar - 20112013). Partimos do pressuposto de que o ensino técnico é um reduto de formação de jovens trabalhadores que procuram meios de inserção no mercado de trabalho. A hipótese que levantamos é que há uma permanência das desigualdades de sexo nesta modalidade de ensino, orientada pelas diferentes escolhas profissionais realizadas por homens e mulheres. Estas escolhas, em geral, são direcionadas pela posição das diferentes carreiras no mundo do trabalho, muitas vezes classificadas, historicamente, entre "femininas" e "masculinas" e relacionadas aos "papéis" que cada sexo assume na família e na sociedade.

Inicialmente, apresentamos uma análise histórica da formação de mulheres no ensino técnico de nível médio. Na sequência, a partir das hipóteses levantadas na primeira parte do texto, analisamos a configuração geral do ensino técnico de nível médio no Brasil, no período 2011-2013, considerando os cursos oferecidos e o número de matrículas nesta modalidade de ensino sistematizadas pelo Censo Escolar INEP/MEC. Por fim, levantamos argumentos sobre os fatores que orientam as escolhas de formação profissional, que mantém algumas áreas como eletrônica e mecânica, por exemplo, como "lugar de homem" e outras, como enfermagem e gestão, como "lugar de mulher".

No Brasil, as barreiras jurídicas e políticas que impediam as mulheres de frequentarem determinados cursos profissionalizantes ou mesmo de se escolarizar, já não são a causa determinante da manutenção das diferenças entre o número de homens e mulheres nos cursos técnicos de nível médio. A profisssionalização está aberta juridicamente para a "livre escolha" dos indivíduos e muito já se avançou quanto a escolarização das mulheres em nível técnico, principalmente, nas últimas quatro décadas. No entanto, a baixa frequência de mulheres em determinados cursos permanece e mostra a latência da desigualdade de sexo em determinadas áreas profissionais.

Cristina Bruschini (2007), em pesquisa sobre as mulheres no ensino profissional, apresenta um panorama das escolhas das carreiras, que contribui para a apresentação do problema que abordamos:

No ensino profissional, os percentuais femininos de conclusão são bastante elevados, sobretudo no ensino técnico, na área de serviços, em várias de suas especialidades, com destaque para Saúde e Artes. Contudo as escolhas das mulheres continuam a recair preferencialmente sobre áreas do conhecimento tradicionalmente "femininas", como educação ( $81 \%$ de mulheres), saúde e bem-estar social (74\%), humanidades e artes $(65 \%)$, que preparam as mulheres para os chamados "guetos" ocupacionais femininos. Mas também é verdade que a parcela feminina nas universidades vem 
ampliando sua presença em outras áreas ou redutos masculinos, como a área de engenharia, produção e construção, na qual aumentou de $26 \%$ para $30 \%$ a presença das estudantes na década considerada (1999-2005) (p.548).

$\mathrm{Na}$ trama da escolha das áreas profissionais, apresentada pela autora, é preciso considerar que o aumento do nível de escolaridade das mulheres não garantiu melhores oportunidades de emprego em relação aos homens, principalmente quando se trata do aumento do número de mulheres em redutos masculinos. Esta diferenciação está bastante vinculada à idéia de que o homem é o provedor da família e o trabalho da mulher assume posição secundária na economia doméstica, o que não se confirma na realidade, uma vez que a maior parte das famílias é mantida ou depende, exclusivamente, do trabalho remunerado das mulheres.

A formação profissional está permeada pelas contingências do mundo do trabalho, para compreendê-la em sua complexidade é preciso considerar que seu desenvolvimento, com suas especificidades, está no bojo do processo de transformação na organização do trabalho produtivo nas últimas décadas.

Laís Abramo (2007), quando trata da inserção das mulheres no mercado de trabalho na América Latina, aponta que, principalmente, a partir da década de 1990, o nível de escolaridade das mulheres na região aumentou, chegando a ser superior ao dos homens e que a participação feminina em ocupações gerais e técnicas têm crescido significativamente. No entanto, destaca a autora, "os mecanismos de segmentação ocupacional que confinam a grande maioria das mulheres nas carreiras menos valorizadas no mercado continuam existindo e se reproduzindo" (p.24).

A partir destas constatações, a questão que se coloca é: por que o aumento da participação das mulheres no mercado de trabalho resultou em um aumento significativo do número de mulheres em empregos precários? Nessa direção, Laís Abramo (2007) apresenta a seguinte constatação:

\begin{abstract}
A manutenção e reprodução das desigualdades existentes entre homens e mulheres no mundo do trabalho são influenciadas por vários fatores, derivados da divisão sexual do trabalho e de uma ordem de gênero que destinam a mulher a função básica e primordial de cuidar da vida privada e da esfera doméstica, e ao mesmo tempo atribuem a esse universo um valor social inferior ao mundo "público" (e desconhecem por completo seu valor econômico). Para as mulheres, isso significa não apenas uma limitação de tempo e de recursos para investir na própria formação e no trabalho remunerado, como também está fortemente relacionado com uma subvalorização (econômica e social) do trabalho feminino e de seu papel na sociedade (p.26).
\end{abstract}

A divisão sexual do trabalho e a "ordem de gênero" que secundarizam a força de trabalho das mulheres em relação aos homens perpassa todas as esferas da vida social, embora muito se tenha avançado quanto a participação no mercado de trabalho, permanece uma Revista Labor Fortaleza/CE, jul/dez 2017 Vol. 01, nº 18, p. 16-30 ISSN 1983-5000 
separação entre homens e mulheres, fundamento da divisão do trabalho no capitalismo, criando limites para a escolha profissional de mulheres no ensino técnico.

Segundo a divisão do trabalho vigente, o conhecimento tecnológico e científico nas áreas de trabalho que dele se ocupam os trabalhadores que o aplicam nas suas atividades, tanto na fábrica e na empresa, como na academia, têm sido associado ao sexo masculino. São posições para poucos nas instituições e, por isso, também, conferem poder e prestígio para os seus ocupantes (LOMBARDI, 2004, p.2-3).

Considerando esta divisão entre trabalho de homens e trabalho de mulheres, analisamos neste artigo a questão da escolha da formação profissional de mulheres no ensino técnico para ingresso em um mercado de trabalho que se abre a elas, por meio das lutas feministas, como aponta Laís Abramo (2007); e para profissões em áreas que se "fecham" a presença delas, como indica Maria Rosa Lombardi (2004).

\section{NOTAS SOBRE A FORMAÇÃO PROFISSIONAL DE MULHERES NO BRASIL}

Como forma de aprofundar a análise sobre as desigualdades entre os sexos na formação profissional no Brasil, será feita, nas páginas que seguem, uma breve retomada histórica da "abertura" da profissionalização em nível médio ${ }^{2}$ para as mulheres. É preciso destacar que neste texto a questão central não é o magistério de crianças pequenas, o objetivo é analisar a formação em profissões mais precisamente vinculadas à indústria e aos serviços, áreas privilegiadas na constituição de cursos em escolas técnicas de nível médio públicas do país. Assim, é preciso assumir, antecipadamente, todos os limites que esse recorte impõe a análise da formação profissional, em especial, quando se trata da formação de mulheres.

As primeiras iniciativas oficiais de educação profissional para as mulheres aconteceram na década de 1880, quando foi inaugurado, no Rio de Janeiro, o primeiro curso específico no Liceu de Artes e Ofícios. Esse acontecimento é contemporâneo das primeiras ações de ampliação do magistério para a formação de mulheres, em especial, aquele voltado para educação de crianças; assim como da abertura de cursos universitários e da organização das primeiras escolas mistas pela Reforma Leôncio de Carvalho (1879).

Foi apenas na década de 1930 que ocorreram os primeiros arranjos sistemáticos para a organização do ensino médio. Até aquele momento, esse nível de ensino estava organizado de forma muito incipiente. Luis Antônio Cunha (2000, p.41) assinala que existiram cursos técnicos oferecidos antes desse período, entretanto, foram as reformas do Estado Novo

${ }^{22} \mathrm{O}$ atual ensino médio era denominado como ensino secundário até a primeira Lei de Diretrizes e Bases da Educação Nacional (LDB) $n^{\circ} .4 .024$ de 1961. Na LDB nº 5.692 de 1971 passou a ser chamado de ensino de $2^{\circ}$. grau e a partir da LDB ${ }^{\circ} .9 .394$ de 1996 de ensino médio.

Revista Labor Fortaleza/CE, jul/dez 2017 Vol. 01, nº 18, p. 16-30 ISSN 1983-5000 
(Francisco Campos - $1932^{3}$ e Capanema - 19424), relativas à educação primária e secundária, que redefiniram o sistema educacional brasileiro, e a partir delas que se desencadeou uma organização mais sistemática da educação. No entanto, as diferenças regionais são, até hoje, determinantes na organização da educação, principalmente quando se trata do desenvolvimento da educação profissional de nível médio.

Ainda no ano de 1942, as regulamentações realizadas pela Reforma Capanema ${ }^{5}$ estabeleciam que o ensino secundário destinado às mulheres fosse realizado, preferencialmente, em instituição exclusiva; que se incluísse a disciplina de economia doméstica nos cursos clássicos e científicos; e que a orientação para os programas a serem oferecidos tivessem em "mira a natureza da personalidade feminina e bem assim a missão da mulher dentro do lar". Observa-se, pelas indicações da legislação, que ainda naquele período a educação para as mulheres estava muito voltada para a esfera privada, para a família, direcionada ao cuidado de educação de crianças pequenas, bem como de outras mulheres e era oferecida de forma exclusiva, separada da escolarização dos homens.

Cabe destacar que a transição do século XIX para o XX foi marcada por importantes transformações econômicas e sociais. No Brasil, o regime republicano é um dos elementos destas mudanças. Em âmbito mundial, as duas guerras mundiais, o processo de urbanização e industrialização dos países Europeus e mais tarde de países latino-americanos contribuíram para a ampliação dos protestos feministas, assim como para reivindicação do voto, do direito à educação e profissionalização de mulheres.

No Brasil, foi a partir da década de 1970 que mudanças mais pujantes aconteceram no acesso das mulheres aos vários níveis da escolarização, e, também, ao ensino técnico de nível médio, no caso brasileiro. Diante da organização, resistência e reivindicação dos movimentos feministas, ocorreu o aumento da participação das mulheres no ensino superior e a definitiva coeducação no ensino secundário, inicialmente de forma bastante incipiente e mais intensamente a partir da década de 1980.

Ocorreu um salto entre as décadas de 1950-1970 quando se trata de escolarização das mulheres, principalmente se tomarmos o ensino superior como referência. Maria Cristina Bruschini (2007), analisando a síntese dos indicadores da PNAD 2007, aponta que "a expansão da escolaridade, à qual as brasileiras têm tido cada vez mais acesso, é um dos fatores de maior impacto sobre o ingresso das mulheres no mercado de trabalho. A escolaridade das

\footnotetext{
${ }^{3}$ Reforma Francisco Campos, Decreto no ${ }^{\circ} 19.890$ de 18 de abril de 1931.

${ }^{4}$ Decreto-Lei $\mathrm{n}^{\circ} 4.244$, de 9 de abril de 1942.

${ }^{5}$ Decreto-Lei $n^{\circ} 4.244$, de 9 de abril de 1942. Título III.

Revista Labor Fortaleza/CE, jul/dez 2017 Vol. 01, nº 18, p. 16-30 
trabalhadoras é muito superior a dos trabalhadores. Em 2005, entre os trabalhadores, 32\% delas, mas 25\% deles, tinham mais de 11 anos de estudo" (p.547-548).

\begin{abstract}
Além das transformações demográficas, mudanças nos padrões culturais e nos valores relativos ao papel social da mulher alteraram a identidade feminina, cada vez mais voltada para o trabalho remunerado. Ao mesmo tempo, a expansão da escolaridade e o ingresso nas universidades viabilizaram o acesso delas a novas oportunidades de trabalho. Todos esses fatores explicam não apenas o crescimento da atividade feminina, mas também as suas transformações no perfil da força de trabalho. (BRUSCHINI, 2007, p. 541).
\end{abstract}

Nas últimas décadas, o número de mulheres no ensino técnico de nível médio também cresceu substancialmente, no entanto, quando analisamos especificamente os cursos nos quais predomina a presença de mulheres, é evidente que ainda há uma continuidade da desigualdade orientada por "papéis de gênero". Cursos que conduzem a postos de trabalho considerados masculinos, como na mecânica e na eletroeletrônica, em geral, são majoritariamente ocupados por homens. Por outro lado, cursos que lidam com habilidades tidas como femininas: cuidar, ensinar, atender pessoas, como enfermagem e administração são ocupados na maioria por mulheres. Qual a justificativa para a permanência desta divisão? Por que as profissões melhor remuneradas e prestigiadas são aquelas "procuradas" pelos homens?

É a partir da década de 1960 que os movimentos feministas e as pesquisas sobre as condições de vida e trabalho das mulheres começam a emergir em diferentes lugares, principalmente na França e nos Estados Unidos. No Brasil, foi a partir da década de 1970 e 1980 que os debates sobre a questão da divisão sexual do trabalho tomaram novas formas e a partir deles emergiram novos estudos e políticas públicas para o ensino voltado às mulheres.

Margarete Maruani (2003) apresenta o seguinte apontamento sobre o período:

É nos anos 60 que aparecem as primeiras pesquisas sobre a atividade feminina. [Na França] as pioneiras se chamavam Madeleine Guilber, Viviane Isambert-Jamati, Andrée Michel. Em seus trabalhos está contido o essencial das rupturas que se expressarão e se problematizarão a partir dos anos 1970. O principal mérito delas foi ter sabido impor a questão das mulheres, no campo das ciências do homem. Fazia-se necessário, portanto, num primeiro momento, sair dessa pré-história das ciências do homem declinadas no masculino neutro para poder entrar no tempo das ciências humanas e considerar a diferença dos sexos (MARUANI, 2003, p.22).

Danièle Kergoat e Helena Hirata (2003), afirmam que a divisão do trabalho entre homens e mulheres como teoria e problemática de pesquisa sociológica emergiu no campo das ciências sociais nos anos 1970 e que trinta anos mais tarde (1990) o termo remete a diversas lógicas cujo inventário ainda está por ser feito (p.111). 
Ainda que hoje os termos do debate sejam outros, "após um acúmulo de trabalhos sobre a articulação das esferas familiares e profissionais, centrada na análise do trabalho feminino, passou-se a uma interrogação sobre a diferença dos sexos no mercado de trabalho. Do estudo do trabalho das mulheres para o estudo das diferenças de sexo" (MARUANI, 2003, p.22).

\begin{abstract}
De forma que já não se trata somente de revelar um segmento da história e da sociologia do trabalho feminino, mas de pôr e impor a questão da diferença dos sexos no cerne das reflexões sobre trabalho e emprego. Com a idéia de que, nas recomposições do mundo do trabalho, bem como nas reflexões sobre o sentido, o valor e o lugar do trabalho na sociedade, a evolução do emprego feminino constitui um elemento determinante (MARUANI, 2003, p.23).
\end{abstract}

Nessa direção, Maria Rosa Lombardi (2004), em estudo sobre as relações de sexo na engenharia brasileira, afirma que foi, sobretudo, a partir da segunda metade do século XX que as relações sociais entre homens e mulheres em coletivos profissionais majoritariamente masculinos constituíram objeto de pesquisa, análises e discussões. Nesse período, observa-se um maior número de mulheres ingressando em cursos universitários e ampliando suas escolhas profissionais para além daquelas áreas de conhecimento nas quais eram tradicionalmente presentes, como era o caso da educação e da saúde, e considerando novas possibilidades de estudo e de futuras carreiras profissionais" (p.2).

A escolarização cumpre historicamente uma função importante na construção da desigualdade entre os sexos e esse processo culmina em determinadas escolhas profissionais. Se observado o percurso da construção das escolas técnicas de nível médio, é possível afirmar que, no Brasil, a formação profissional nesse nível se construiu para atender, especialmente, a formação dos homens, enquanto as profissões majoritariamente femininas foram secundarizadas.

No decorrer do desenvolvimento do capitalismo foram se constituindo profissões desenvolvidas majoritariamente por mulheres, grande parte delas relacionada à esfera reprodutiva, dentre elas estão atividades que, pouco a pouco, foram assumindo característica de função assalariada, como o trabalho doméstico. Ao mesmo tempo em que as mudanças no setor produtivo foram transformando profissões exclusivamente ou majoritariamente masculinas em profissões mistas ou femininas, sendo que nesse processo elas passaram por forte desvalorização social.

A profissionalização e a escolha da carreira não podem ser imputadas as escolhas individuais das mulheres, é uma construção histórica e social que percorre toda a constituição do ser mulher em nossa sociedade e do significado das profissões exercidas por mulheres. Há 
um corte social, uma divisão desigual entre o que está "reservado" para os homens e o "reservado" para as mulheres, em especial, no mercado de trabalho.

Há que se considerar na análise do aumento da participação das mulheres no mercado de trabalho, que o trabalho doméstico nunca deixou de ser imputado a elas, permaneceu não remunerado e ocorre simultaneamente a atividade profissional, significando, para a maioria das mulheres, o exercício da dupla jornada: atividade profissional e doméstica.

\section{PARTICIPAÇÃO DAS MULHERES NO ENSINO TÉCNICO - CENSO ESCOLAR INEP/MEC 2011-2013}

Apresentamos nas páginas que seguem os dados de matrículas no ensino técnico de nível médio no Brasil, entre os anos de 2011 e 2013, separados por eixos tecnológicos e por sexo. Os gráficos não estão discriminados entre público e privado, trata-se do conjunto de matrículas nessa modalidade de ensino, captadas e sistematizadas pelo Censo Escolar realizado pelo Instituto Nacional Estudos e Pesquisas Educacionais Anísio Teixeira (INEP/MEC) 6 entre os anos de 2011 e 2013. Os gráficos nos auxiliam na localização das matrículas de mulheres no ensino técnico de nível médio e comprovam a hipótese levantada na primeira parte do trabalho de que as mulheres estão concentradas em determinadas áreas do ensino técnico de nível médio, em especial àquelas vinculadas ao cuidado.

O gráfico 1, apresentado a seguir, mostra o montante de matrículas no ensino técnico de nível médio discriminadas por sexo. Observa-se que ocorreu um aumento significativo nas matrículas nesta modalidade de ensino no período selecionado e que a maioria delas foi ocupada por mulheres.

\section{GRÁFICO 1}

${ }^{6}$ Disponível em: http://portal.inep.gov.br/. Acesso em 01 de fevereiro de 2017.

Revista Labor Fortaleza/CE, jul/dez 2017 Vol. 01, n 18, p. 16-30 ISSN 1983-5000 


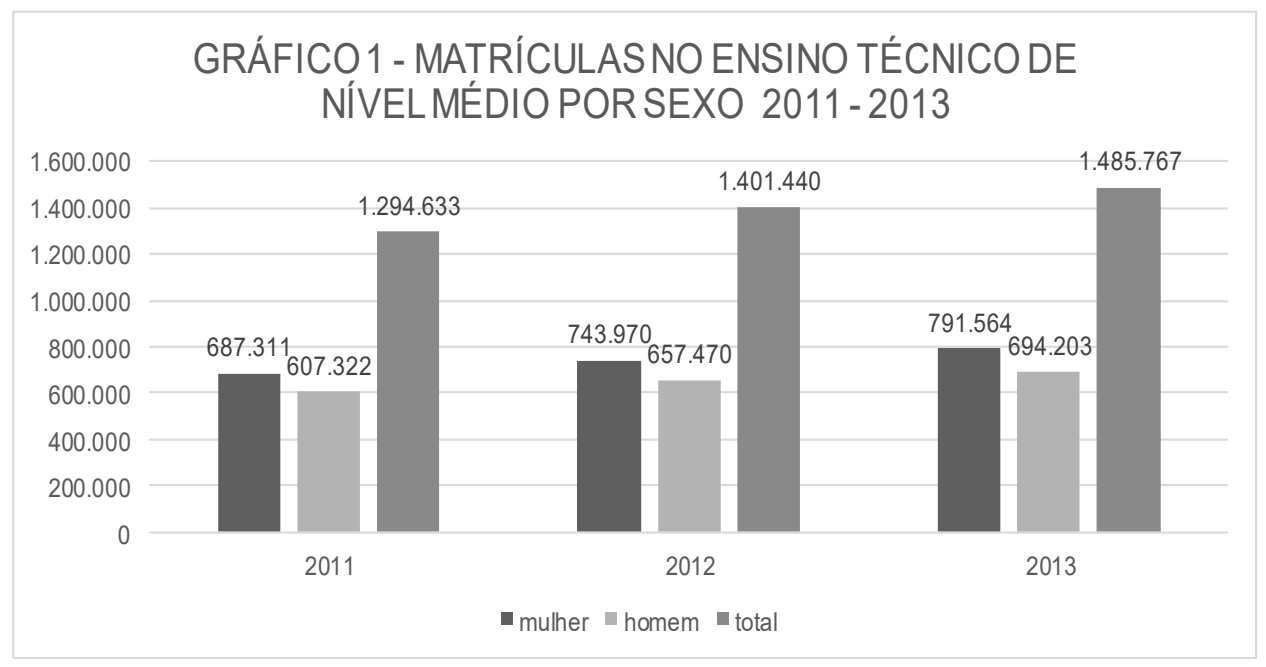

FONTE: CENSO ESCOLAR INEP/MEC - 2011-2013. ELABORAÇÃO PRÓPRIA.

Separamos o montante de matrículas por eixos tecnológicos com o objetivo de extrair um panorama geral da posição de homens e mulheres no interior do ensino técnico de nível médio, procurando verificar se as hipóteses levantadas na primeira parte do texto se confirmavam no período analisado.

É preciso destacar que a organização dos cursos técnicos de nível médio em eixos tecnológicos tem sua origem legal no Parecer CNE/CEB $n^{0} .11 / 2008$, por meio do qual o Conselho Nacional de Educação respondeu a proposição da Secretaria de Educação Profissional e Tecnológica do Ministério da Educação (SETEC/MEC) de criação do Catálogo Nacional de Cursos Técnicos. O parecer foi antecedido por uma consulta pública nacional que ficou disponível no site do MEC durante noventa dias.

O referido parecer originou a Resolução CNE/CEB n ${ }^{\circ}$. 3/2008, que disciplinou a instituição e implantação do Catálogo Nacional de Cursos Técnicos. Essa resolução que regulamentou o catálogo foi alterada, posteriormente, a partir do Parecer CNE/CBE nº. 3/2012, que originou a Resolução CNE/CEB no 4/2012, definindo uma nova versão do Catálogo Nacional, alterando os eixos tecnológicos e incluindo 44 novos cursos técnicos no catálogo. Atualmente vigora a configuração dos eixos tecnológicos estabelecida pela resolução de 2012. Foram criados trezes eixos tecnológicos, são eles: ambiente e saúde; desenvolvimento educacional e social; segurança; controle e processos industriais; gestão e negócios; hospitalidade e lazer; informação e comunicação; infraestrutura; produção alimentícia; produção cultural e design; produção industrial; militar e recursos naturais. 
Atualmente, a nomenclatura dos cursos, a carga horária, as possibilidades de temas a serem abordados na formação, as possibilidades de atuação e a infraestrutura recomendada para a realização dos cursos são reguladas pelo Catálogo Nacional de Cursos Técnicos ${ }^{7}$.

No ano de 2011, a configuração das matrículas por eixo tecnológico era a seguinte:

GRÁFICO 2

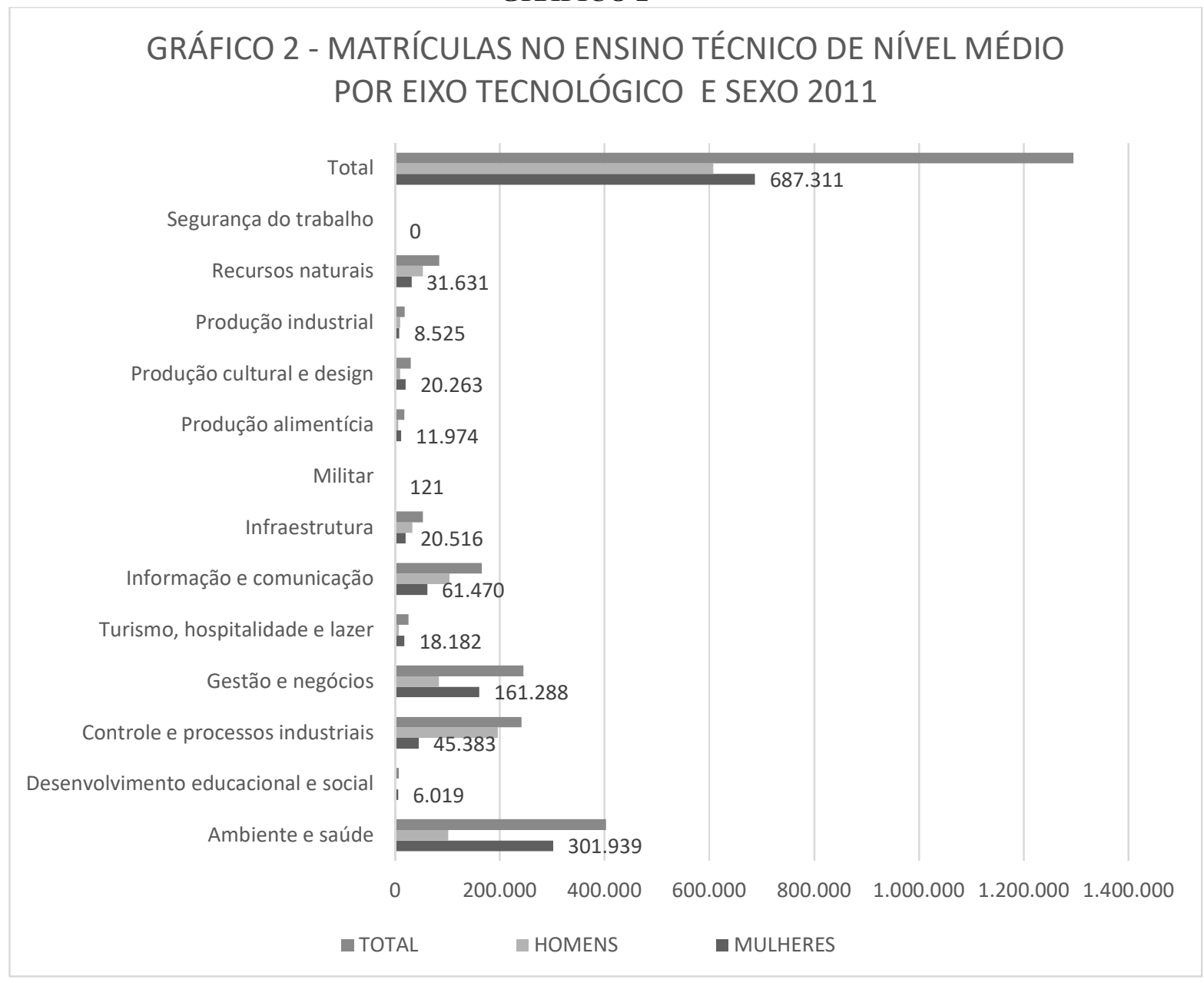

FONTE: CENSO ESCOLAR INEP/MEC - 2011-2013. ELABORAÇÃO PRÓPRIA.

Os dados de matrículas por eixo tecnológico indicam que, no ano de 2011, as mulheres compunham a maioria dos estudantes do ensino técnico de nível médio e estavam concentradas, principalmente, nos seguintes eixos tecnológicos: ambiente e saúde; gestão e negócios e informação e comunicação.

Vejamos a seguir os dados referentes aos anos de 2012 e 2013:

\section{GRÁFICO 3}

\footnotetext{
${ }^{7}$ Disponível em: http://portal.mec.gov.br/catalogo-nacional-de-cursos-tecnicos. Acesso em 01 de fevereiro de 2017.

Revista Labor Fortaleza/CE, jul/dez 2017 Vol. 01, nº 18, p. 16-30 ISSN 1983-5000
} 


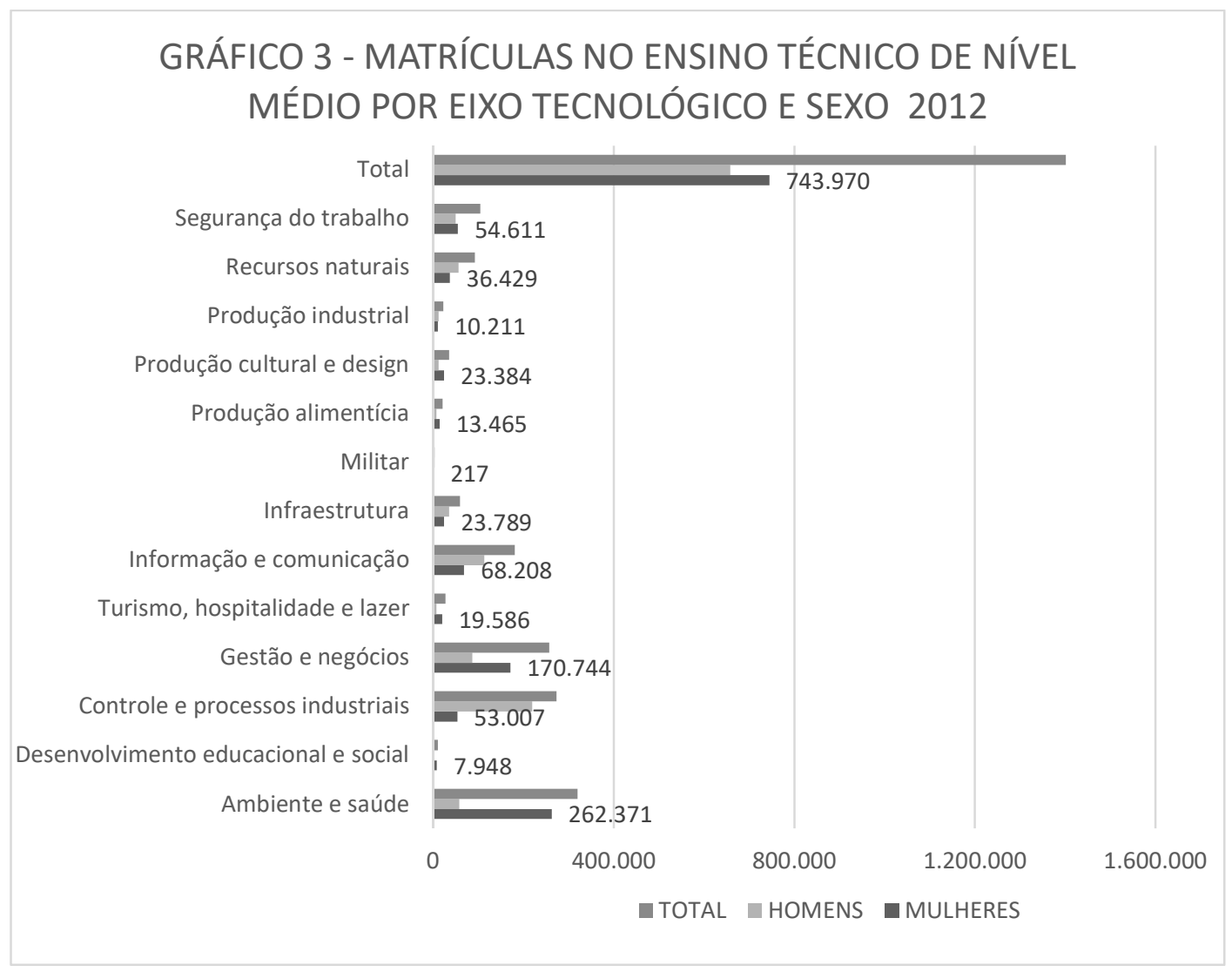

FONTE: CENSO ESCOLAR INEP/MEC - 2011-2013. ELABORAÇÃO PRÓPRIA.

\section{GRÁFICO 4}

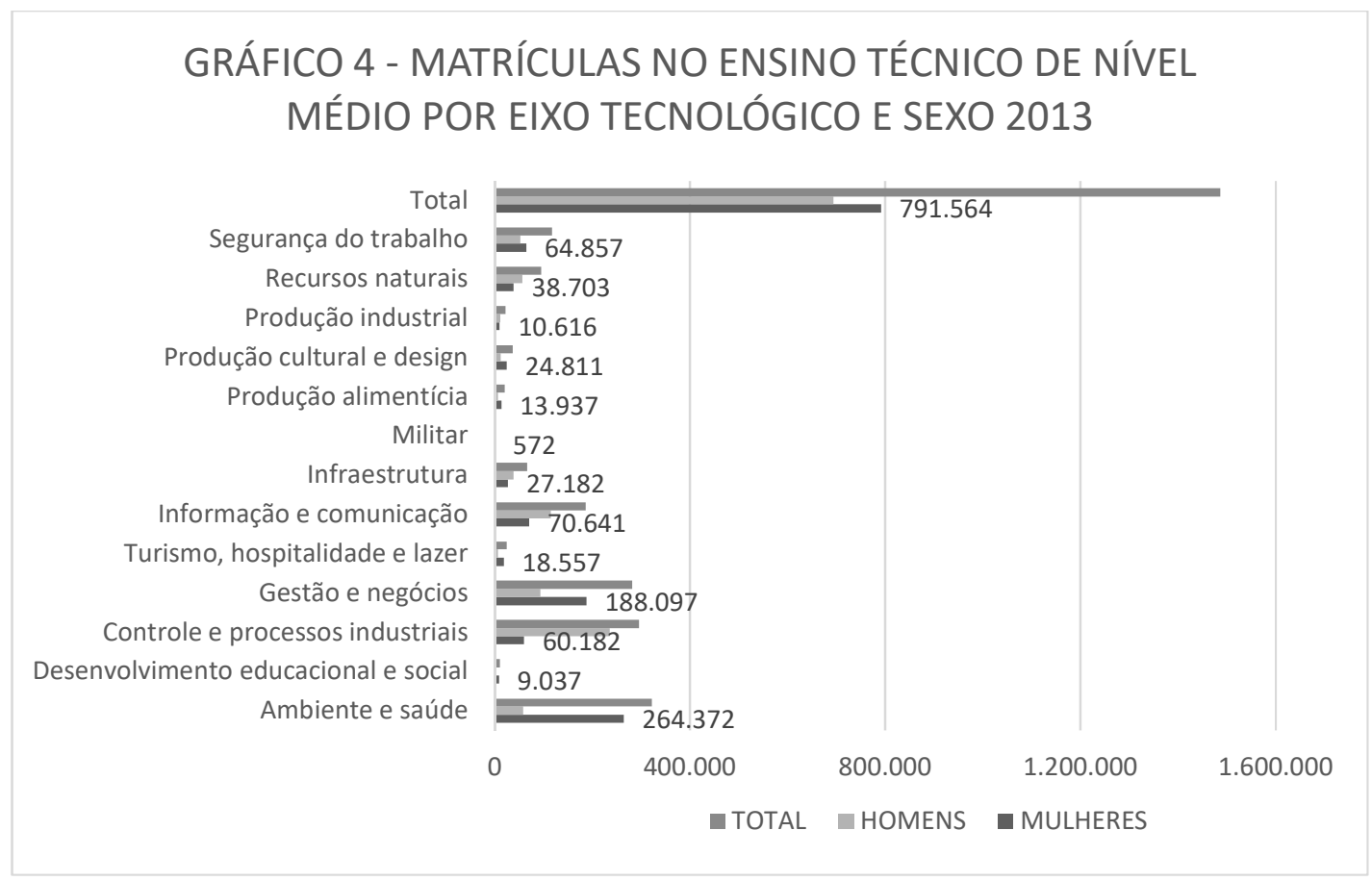

FONTE: CENSO ESCOLAR INEP/MEC - 2011-2013. ELABORAÇÃO PRÓPRIA. 
A concentração das matrículas de mulheres nas áreas indicadas anteriormente, com destaque para ambiente e saúde, mantém-se nos anos de 2012 e 2013. O aumento de matrículas de mulheres também ocorreu nas áreas indicadas. É importante observar que uma área que não tinha expressão em 2011, segurança do trabalho, ampliou-se com a participação majoritária de mulheres.

As áreas que abrigam a maioria das mulheres, ambiente e saúde (29 cursos); gestão e negócios (17 cursos) e informação e comunicação (9 cursos), possuem, em conjunto, cinquenta e cinco (55) opções de cursos. Os dados de matrícula do ano de 2013 indicam que dentre os cursos da área de ambiente e saúde, os homens são a maioria somente nos cursos de órtese e prótese e equipamentos biomédicos, o restante dos cursos é composto majoritariamente por mulheres. É nesta área que está localizado o curso de enfermagem, responsável pelo oferecimento da maior quantidade de matrículas no ensino técnico de nível médio no país.

No eixo de gestão e negócios as mulheres são a maioria em todos os cursos. Os três cursos com maior quantidade de matrículas de mulheres são: administração, contabilidade e logística. São cursos que registram significativa quantidade de matrículas no ensino técnico de nível médio. Outros dois cursos que se destacam em número de matrículas neste eixo são: secretariado e recursos humanos.

No eixo tecnológico informação e comunicação ocorre o inverso do eixo ambiente e saúde, os homens são a maioria em grande parte dos cursos, as mulheres são a maioria somente nos cursos de serviços aeroportuários e geodésia e cartografia. No entanto, as mulheres têm uma participação expressiva no curso de edificações, por isso, o número de matrículas de mulheres neste eixo é tão significativo.

Observamos que o curso de enfermagem é o principal responsável pela presença majoritária das mulheres no ensino técnico de nível médio, ainda que tenhamos verificado a presença expressiva em outros cursos que não são ocupados tradicionalmente por mulheres, como edificações. No ano de 2013, foram oferecidas 157.834 matrículas no curso de enfermagem, sendo que 136.841 matrículas foram ocupadas por mulheres. No eixo tecnológica ambiente e saúde há outros cursos ocupadas principalmente por mulheres, como estética, farmácia e massoterapia que oferecem uma quantidade expressiva de matrículas. As mulheres estão localizadas, sobretudo, neste eixo tecnológico, relacionado ao cuidado, que abriga profissões historicamente ocupadas por mulheres.

Verificamos que o número de matrículas no ensino técnico de nível médio vem aumento significativamente e que as mulheres estão presentes na maioria dos cursos, no 
entanto, a maioria ainda se concentra nos cursos indicados anteriormente, tradicionalmente ocupados por mulheres.

\section{CONSIDERAÇÕES FINAIS}

Nas últimas décadas, mudanças significativas aconteceram na escolarização das mulheres. Desde a década de 1970 está ocorrendo um aumento do número de mulheres no ensino técnico e no ensino superior, assim como no mercado de trabalho, isso é inegável e indissociável. No entanto, há uma dupla dimensão: "de um lado a conquista de bons empregos, o acesso a carreiras e profissões de prestígio e a cargos de gerência, e mesmo de diretoria, por parte de mulheres escolarizadas, e de outro o predomínio do trabalho feminino em atividades precárias e informais" (BRUSCHINI e LOMBRADI, 2007, p. 45).

Helena Hirata (2010) afirma que o aumento da participação das mulheres no mercado do trabalho está associado a flexibilização e a precarização do trabalho, ou seja, a retirado da proteção social e dos direitos sociais relativos ao emprego. Para a autora, a precarização do trabalho que atinge a categoria dos empregados deve ser correlacionada à sua composição sexuada, assim evidencia-se que as mulheres ocupam os postos mais desvalorizados.

As pesquisas sobre a divisão sexual do trabalho consultadas apontam um avanço quando se trata da escolarização das mulheres, no entanto, também indicam que a formação profissional delas está concentrada nas áreas da saúde e gestão e que aquelas profíssões vinculadas à indústria e à informática permanecem majoritariamente masculinas. Observamos nas estatísticas apresentadas no item anterior, que essa situação se confirma no caso brasileiro, no período 2011-2013. Há que se considerar que o ensino técnico de nível médio representa o momento em que se iniciam as escolhas profissionais, cuja possibilidade dela se consolidar no ensino superior e, posteriormente, no mercado de trabalho é bastante alta.

As estatísticas elaboradas pelo IBGE têm mostrado que as diferenças salariais entre homens e mulheres têm diminuído no decorrer dos últimos anos, entretanto, quanto maior a qualificação exigida pela carreira, maior é a diferença salarial entre os sexos (MANDALOZZO et al, 2010).

O percurso profissional está marcado pelas mudanças no significado de ser mulher e ser homens na sociedade contemporânea. A escolarização e profissionalização das mulheres têm avançado ao passo em que avança a luta feminista contra a dominação masculina. Ao ingressar na escola as meninas e meninos já sabem qual é a sua identidade sexual e o significado 
social dessa identidade. E a escola colabora com essa definição, agindo na formação intelectual e social dos indivíduos, ou seja, tornando-os adequados aos próprios modelos culturais (MORENO, 1999, p.17).

Montserrat Moreno (1999) coloca que as constituições científicas da realidade, ou seja, uma verdade sobre o movimento da realidade se constrói, muitas vezes, como peças de um quebra cabeça ideológico de uma determinada época e isso responde às necessidades do sistema de organização das sociedades. A desigualdade não se localiza na escolha da profissão em si, ela está na base da divisão do trabalho no capitalismo. É precisamente uma metade da humanidade que possui a força (os exércitos, a polícia), domina os meios de comunicação de massa, detém o poder legislativo, governa a sociedade, têm em suas mãos os principais meios de produção, é o dono e senhor da técnica e da ciência (p.23)

Nas brincadeiras as meninas podem escolher em ser professoras, enfermeiras, cozinheiras, babás, secretárias, etc., enquanto os meninos elegem entre policiais, bombeiros, engenheiro, médico, esportistas, etc. "Se os meninos e meninas tendem a identificar-se com os modelos vigentes em nossa sociedade e isso se manifesta no jogo, se os jogos são tão diferentes, é necessário admitir que existem modelos diferentes para uns e para outros no que concerne a essa característica" (MORENO, 1999, p.32).

Existe uma hierarquia de gênero que perpassa todas as dimensões da vida social de homens e mulheres. Não é possível analisarmos as diferenças entre a profissionalização dentre os sexos sem pensarmos na divisão sexual do trabalho, o que, no caso das mulheres, inclui o trabalho doméstico e o cuidado com os filhos, que não são remunerados e são entendidos socialmente e ensinados como um dever (incontestável). E como indicam Danièle Kergoat e Helena Hirata (2007), esses dois aspectos do trabalho feminino (profissional e doméstico) não podem ser pensados simplesmente em termo de "conciliação" de duas atividades, mas sim de duas dimensões da mesma, o trabalho.

As condições das mulheres têm mudado significativamente e aqui não se pretende negar esse fato ou simplesmente minimizá-los, entretanto, a distância que separa homens e mulher permanece. O que é estável não são as situações (que evoluem sempre), e sim a distância entre os grupos de sexo, como bem sinalizaram Kergoat e Hirata (2007, p.560) quando tratam da sociedade francesa. Existe uma desigualdade entre homens e mulheres no trabalho profissional e é preciso considerá-la para se compreender a divisão entre os sexos na formação profissional. 
Levantou-se nesse texto hipóteses acerca das relações entre a divisão sexual do trabalho e a formação profissional no ensino técnico de nível médio, são ponderações preliminares que exigem levantamentos e pesquisa mais aprofundada. É preciso refletir sobre as desigualdades e compreender o sentido dessas permanências que afetam todas as dimensões da vida de mulheres e homens, para superá-las.

\section{BIBLIOGRAFIA}

ABRAMO, Laís. Inserção das mulheres no mercado de trabalho na América Latina: uma força de trabalho secundária? In: HIRATA, H. e SEGNINI, L. Organização, trabalho e gênero. São Paulo: SENAC/SP, 2007.

BRUSCHINI, C. e LOMBARI, M.R.. Trabalho, educação e rendimentos das mulheres no Brasil em anos recentes. In: HIRATA, H. e SEGNINI, L. Organização, trabalho e gênero. São Paulo: SENAC/SP, 2007.

CUNHA, Luiz Antônio. O ensino dos ofícios nos primórdios da industrialização. São Paulo: UNESP; Brasília: FLACSO, 2000.

HIRATA, Helena. A precarização e a divisão internacional e sexual do trabalho. Sociologias, Porto Alegre, ano 11, nº 21, jan./jun. 2009, p. 24-41.

KERGOAT, Danièle e Helena, HIRATA. Novas configurações da divisão sexual do trabalho. Cadernos de Pesquisa, v. 37, n. 132, set./dez. 2007, p. 595-609.

LOMBARDI, M.R. Perseverança e resistência: a engenharia como profissão feminina. Campinas/SP, 2004. Tese de doutorado.

MANDALOZZO, Regina; MARTIN, Sérgio e SHIRATORI, Ludmila. Participação no Trabalho doméstico: homens e mulheres têm condições iguais? Estudos Feministas, Porto Alegre, 18(2), maio/ago, 2010.

MARUANI, M. e HIRATA, H. As novas fronteiras da desigualdade: homens e mulheres no mercado de trabalho. São Paulo: Senac SP, 2003.

MORENO, Montserrat. Como se ensino a ser menina: o sexismo na escola. São Paulo: Moderna, 1999. 